\title{
Research on Internal Medicine and Cultivation of Innovation Ability of College Students Based on MIT Teaching Model
}

\author{
Lihong Zhang ${ }^{1}$, Zhe Liu ${ }^{2}$, Chun Feng ${ }^{1 *}$
}

${ }^{1}$ Harbin Medical University, Affiliated Hosp 5, Daqing Peoples Hosp, Dept Gastroenterol, 213 Jianshe Rd, Daqing, Heilongjiang 163316, P.R. China

${ }^{2}$ College of Life Science and Technology, Heilongjiang Bayi Agricultural University, 2 Xinfeng Rd, Daqing, Heilongjiang 163319, P.R. China

\author{
DOI: $10.36347 /$ sasjm.2020.v06i10.001 \\ | Received: 28.06.2020 | Accepted: 06.07.2020 | Published: 17.10.2020
}

*Corresponding author: Chun Feng

Abstract

Taking the course of internal medicine as an example, this paper studies the cultivation mode of medical undergraduates' quality and ability under the thinking of internet. Through the establishment of mobile interactive teaching research of technology (MIT) model, to better cultivate qualified talents, training medical undergraduate students operation ability, cultivate undergraduate students innovative thinking, enhance the level of the medical undergraduate cultivation of innovative talents, MIT mode operation ability is the effective way to improve the innovative ability training of medical talent.

Keywords: Internet thinking; Specimens of plants and animals; Cultivation mode; Innovation ability.

Copyright ( $\odot 2020$ The Author(s): This is an open-access article distributed under the terms of the Creative Commons Attribution 4.0 International License (CC BY-NC 4.0) which permits unrestricted use, distribution, and reproduction in any medium for non-commercial use provided the original author and source are credited.

\section{INTRODUCTION}

Under the background of the era of internet information technology, there is a new situation in higher education. The emergence of the new trend of MIT (Mobile interactive teaching) provides a good idea for us to solve the problem of operation technology teaching in the course of internal medicine. "MIT" changed the traditional teaching mode and methods in the context of the internet, allowing mobile phones into the classroom, interspersing Internet teaching with the classroom [1-3], and achieving a good teaching effect. Teachers can impart a lot of information through the internet platform, thus promoting the reform of modern teaching model. Under the "MIT" teaching model, students get more and deeper information and ideas. This paper discusses the teaching mode and exploration of operation ability under the mobile interactive teaching of the course of internal medicine, so as to cultivate college students' ability of innovation and entrepreneurship. It is introduced as follows.

\section{Establish the "MIT" model}

According to the characteristics of the experimental course of "internal medicine" and centering on the training goal of medical professionals, a research object with medical students as the main body was formed, and the experimental group and the control group were randomly selected. Teachers can listen to experts' opinions, improve the teaching model through information guidance, make it more scientific in demonstration teaching, and guide students to explore a lot of new information [4, 5]. Through the research and establishment of "MIT" teaching mode, so as to better train qualified personnel. At the same time, the research of the subject can promote the adjustment and improvement of teaching institutions, and provide scientific basis for the teaching reform of medical specialty and related disciplines [6].

"MIT" mode operation requires software such as superstar Learning Pass"in the context of mobile network or wireless network. In addition, the medical operation experiment teaching process implemented by Learning Pass is more dependent on the subjective initiative of students, and the cramming teaching method is changed. With "MIT" teaching reform, in this era of internet information technology has become a reality. The combination of new teaching methods and information-based teaching tools will continue to explore more effective ways and methods of teaching, providing the most basic conditions for the application of "MIT" teaching mode in medical operation teaching [7].

\section{"MIT" mode teaching approach and course design of medical operation \\ Teachers and students download and install the "Learning Pass" APP for registration. Teachers create a course of internal medicine, and use the invitation code}


to ask students to join the class course. Students can consult resources, participate in activities, and be enrolled by the teacher thumb up in the class course [8]. Teachers can publish course-related resources through APP platform, such as animation, courseware and specimen making works. Teachers can also arrange tasks, discussions and other teaching activities in the activity options to stimulate students' thinking and save time for group reorganization in class. To guide students, make mobile phones become a learning tool for students and provide a way out for cultivating application-oriented talents [9].

Teachers upload related resources and learning tasks of medical operation in "Learning Pass" channel. The uploaded resources can include pictures, animations, etc. Through the class course to send out the notice, put forward the task requirements, at the same time the release of classroom exercises. Also can carry on the classroom discussion, studies the case, and so on, makes good use of the mobile phone, enables the student to absorb the nutrition from the mobile phone, and enhances the interaction.

During the course, teachers can learn the contents of blood pressure measurement, key physical examination, peritoneum puncture, painless gastroscope, general anaesthesia and enteroscopy through the resources and animations in "Learning Pass", which improves the learning efficiency of basic skills and integrates the needs of the times. Students are more receptive to the operational skills needed in internal medicine. Take internal medicine operation as an example to see the teaching implementation of "MIT" mode in class. Students in the experimental group who adopted the "MIT" teaching mode showed significant improvement in the efficiency of operational skills, the ability to accept problems, the ability of thinking, communication and discussion, and the awareness of innovation.

Teachers can create students' discussion activities by adding activities in the "Learning Pass" APP. In classroom teaching, teachers choose to divide into groups, and students complete tasks in groups, such as discussing the process of operation skills, and submit the task results. Students' groups use mutual assessment or teachers' comments to evaluate the tasks completed by the group [10-12]. In the limited time of class, teachers can learn about students' knowledge and make evaluation through "Learning Pass". Teachers create group task details, students use internal medicine knowledge to practice the corresponding training.

The implementation of "MIT" mode classroom allows teachers to analyze the materials and other resources in the course resources. This process is the key point of education. Many classroom activities can be carried out through "Learning Pass", and the efficiency and effect of classroom activities can be improved with information technology. For example, the brainstorming activity allows students to participate in thinking. Using the new test to test students, according to the results submitted by students to understand the learning situation, teachers targeted to explain the key points of knowledge. Discussion and answering questions break through the limitation of time and space, teachers and students can exchange knowledge at any time.

Implement "MIT" classroom to improve the quality of classroom teaching and achieve the educational purpose. Students can check in with one key or gesture in the "Learning Pass" and preview before class. On the internet, teachers and students were shown "peritoneocentesis" and asked questions. Students thought: "how to conduct peritoneocentesis? Precautions?" and so on. Students can also upload questions to teachers through "Learning Pass". By implementing the "MIT" mode of medical operation through "Learning Pass", students can meet their individual needs through "Learning Pass", attach importance to students' learning process, mobilize their interest in learning and stimulate their enthusiasm for learning, which is conducive to the communication between teachers and students and students. By acquiring the "experience value" of "Learning Pass", students can improve their learning initiative. By using the "MIT" mode of medical operation to help teachers, the teaching process can be recorded and a teaching report can be formed to objectively reflect the teaching process and students' learning process.

In short, the innovation of this project is to combine "MIT" model is applied to the teaching of medical operation, sufficient and reasonable use of network in a wide range of resources, based on the current teaching system in our country, explore a new mode suitable for medical undergraduate course teaching in our school, and promote medical school science curriculum teaching quality and the improvement of college students' practical and innovative ability.

\section{ACKNOWLEDGMENTS}

This work was supported by grants from the Heilongjiang Bayi Agricultural University Team Support Program for San Heng San Zong(TDJH201905) and Heilongjiang Bayi Agricultural University Support Program for San Heng San Zong(ZRCPY201909). All of the authors have read the manuscript and have agreed to submit it, in its current form, for consideration for publication.

\section{REFERENCES}

1. Goldberg LR, Crocombe LA. Advances in medical education and practice: role of massive open online courses. Adv Med Educ Pract. 2017, 8: 603-609. 
2. Zhao G, Jiang Z. From e-campus to e-learning: an overview of ICT applications in Chinese higher education. Br J Educ Technol.2010, 41: 574-581.

3. Branch WT Jr, Paranjape A. Feedback and reflection: teaching methods for clinical settings. Acad Med. 2002, 77(12 Pt 1):1185-8.

4. Baroffio A, Kayser B, Vermeulen B, Jacquet J, Vu NV. Improvement of tutorial skills: an effect of workshops or experience? Acad Med. 1999,74(10 Suppl):S75-7.

5. Meyer JHF, Land R. Threshold concepts and troublesome knowledge (1) - Linkages to ways of thinking and practicing. In: Improving Student Learning Theory and Practice-10 Years On, edited by Rust C. Oxford: OCSLD, 2003.

6. Turk B, Ertl S, Wong G, Wadowski PP, LöfflerStastka H. Does case-based blended-learning expedite the transfer of declarative knowledge to procedural knowledge in practice? BMC Med Educ. 2019, 3;19(1):447.

7. Rouleau G, Gagnon MP, Côté J, Payne-Gagnon J, Hudson E, Dubois CA, Bouix-Picasso J. Effects of E-Learning in a Continuing Education Context on Nursing Care: Systematic Review of Systematic Qualitative, Quantitative, and Mixed-Studies Reviews. J Med Internet Res. 2019, 2;21(10):e15118.
8. McLaughlin JE, Gharkholonarehe N, Khanova J, Deyo ZM, Rodgers JE. The impact of blended learning on student performance in a cardiovascular pharmacotherapy course. Am J Pharm Educ.2015, 79: 24.

9. Rusiecki J, Schell J, Rothenberger S, Merriam S, McNeil M, Spagnoletti C. Acad Med. An Innovative Shared Decision-Making Curriculum for Internal Medicine Residents: Findings From the University of Pittsburgh Medical Center. 2018, 93(6):937-942.

10. Dzara K, Chen DT, Haidet P, Murray H, Tackett S, Chisolm MS. The Effective Use of Videos in Medical Education. Acad Med. 2019, 29. doi: 10.1097/ACM.0000000000003056.

11. Chen J, Zhou J, Wang Y, Qi G, Xia C, Mo G, Zhang Z. Blended learning in basic medical laboratory courses improves medical students' abilities in self-learning, understanding, and problem solving. Adv Physiol Educ. 2020 Mar $1 ; 44(1): 9-14$.

12. Giuliodori MJ, Lujan HL, DiCarlo SE. Peer instruction enhanced student performance on qualitative problem-solving questions. Adv Physiol Educ.2006, 30: 168-173. 